\title{
The Effect of Virtual Users' Autonomous Adaptive Behavior on Atypical Architectural Design in the Architectural Design Studio
}

\author{
Yun Gil Lee ${ }^{1}$ \\ ${ }^{1}$ Associate Professor, Department of Architecture, Hoseo University, Republic of Korea, \\ yglee@hoseo.edu
}

\begin{abstract}
The design procedure of atypical building is quite dissimilar from the conventional buildings because the architect must solve more problems than normal. Sometimes, they overlook the human factors which is the one of the most significant standard to evaluate the value of buildings. To solve this problem, simulation technology using virtual human-shaped agent(Virtual User) is recommended. Virtual users' interactions like a real world in the process of architectural design can help designers come up with new ideas, so the behavior of virtual users significantly influences the design process and results. In other words, the virtual users' adaptive behavior, which is more natural reaction to architectural geometry, is an significant factor for defining the value of human behavior simulations. In the previous study, the researchers developed a function that enables adaptive behavior by virtual agents in ActoViz. This function was developed to simulate human behavior during the design of atypical architectural spaces. However, the effect of adaptive behavior on the design process and the final design have not yet been investigated. Therefore, the present research aimed to evaluate the effect of virtual users' autonomous adaptive behavior on creative problem finding during the design process. In this study, 35 students were asked to use ActoViz's adaptive behavior function when designing an atypical space. The students then responded to a questionnaire about creative problem finding before and after using the function. The result of the survey showed that the adaptive behavior function helped designers create new shapes and identify more functions for their designs. This suggests that the adaptive behavior function helped designers develop new forms. The survey results also indicated that the adaptive behavior function helped designers identify problems in their designs, increasing their self-assurance in the designs' safety and suitability. This is because the adaptive behavior function expresses the physical situation better than other behavior simulations.
\end{abstract}

Keywords: Adaptive Behavior, Virtual User, Atypical Design, Architectural Space, Behavior Simulation

\section{Introduction}

Atypical architectural space can be easily found in our surroundings nowadays just like in [Fig. 1]. The ability to design atypical architectural space is important to students in the deparment of architecture as well as the professional architect because social demend for atypical architectural space is growing accordingly. However, the design procedure of atypical building is quite different from the conventional buildings because the architect must solve more problems than normal. Sometimes, they overlook the human factors which is the one of the most substantial standards in evaluating the value

Received: September 02, 2020; $1^{\text {st }}$ Review Result: October 26, 2020; $2^{\text {nd }}$ Review Result: December 10, 2020 Accepted: January 25, 2021 
of buildings[1][2]. To solve this problem, simulation technology using virtual human-shaped agent (Virtual User) is recommended. Traditionally, human shaped images have been always used in the design process to evaluate the designed alternatives and to let the clients understand easily the idea of the architects. Virtual user is a kind of intelligent agent which behave freely on the the designed architectural space. The ultimate goal of this research is to develop an intelligent agent like human in the atypical architectural space.

When students plan architectural spaces, the presence of a human-shaped virtual agent can help them design creative, unexpected shapes, discover various usages for the design, develop confidence in the usefulness of these functions, and develop self-assurance in the safety and suitability of the design[3]. Appropriate interactions between the designed building and the virtual agent can help designers come up with new thoughts, so the behavior of the virtual user significantly influences the design process and the final design. In other words, virtual users must engage in adaptive behavior for the human behavior simulation to be valuable. [Fig. 2] shows the human behavior simulation system (ActoViz) developed in the former study[4]. In this study, functions to create virtual users' adaptive behavior were developed. The functions were developed in ActoViz to create a human behavior simulation during the design of atypical spaces. However, the effects of this adaptive behavior on the design process and the design have not been investigated. Therefore, the present research aimed to evaluate the effect of a virtual user's autonomous adaptive behavior on the creative identification of problems during the design process and on the final design. In this study, students were asked to use the ActoViz adaptive behavior function during class. They responded to a questionnaire about creative identification of problems before and after they used the function.

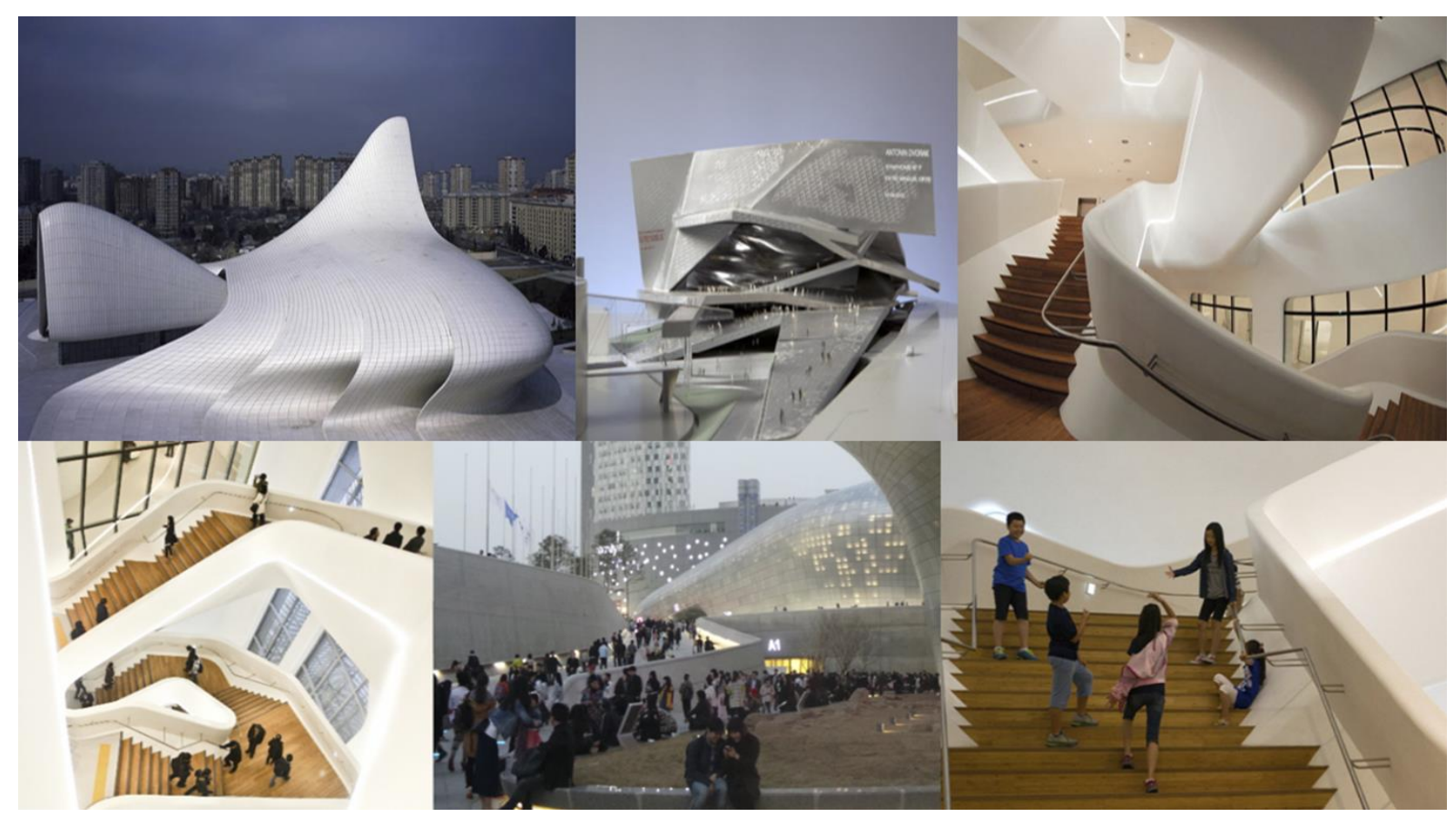

[Fig. 1] Examples: Exterior and Interior of Atypical Architectural Space

\section{Atypical Architectural Design \& Human Behavior Simulation}

Traditionally, the architectural design process consists of repetitive evaluation and revision of design results. There are various criteria for reviewing design results, among which human factor can be said to be the top priority. The standard for reviewing the performance of human factors in design results is generally based on building codes or the architect's experience. However, building codes are 
difficult to sufficiently reflect the changing life style with a fixed minimum standard. The architect's experience cannot be generalized, and objective proof is impossible. In order to overcome this limitation of human factor evaluation in the architectural design process, a human factor evaluation based on virtual users appeared. The evaluation of human factors using intelligent virtual users has been studied by many researchers and its effectiveness has been proven. [Fig. 2] shows an example of user behavior simulation through an intelligent agent[3].

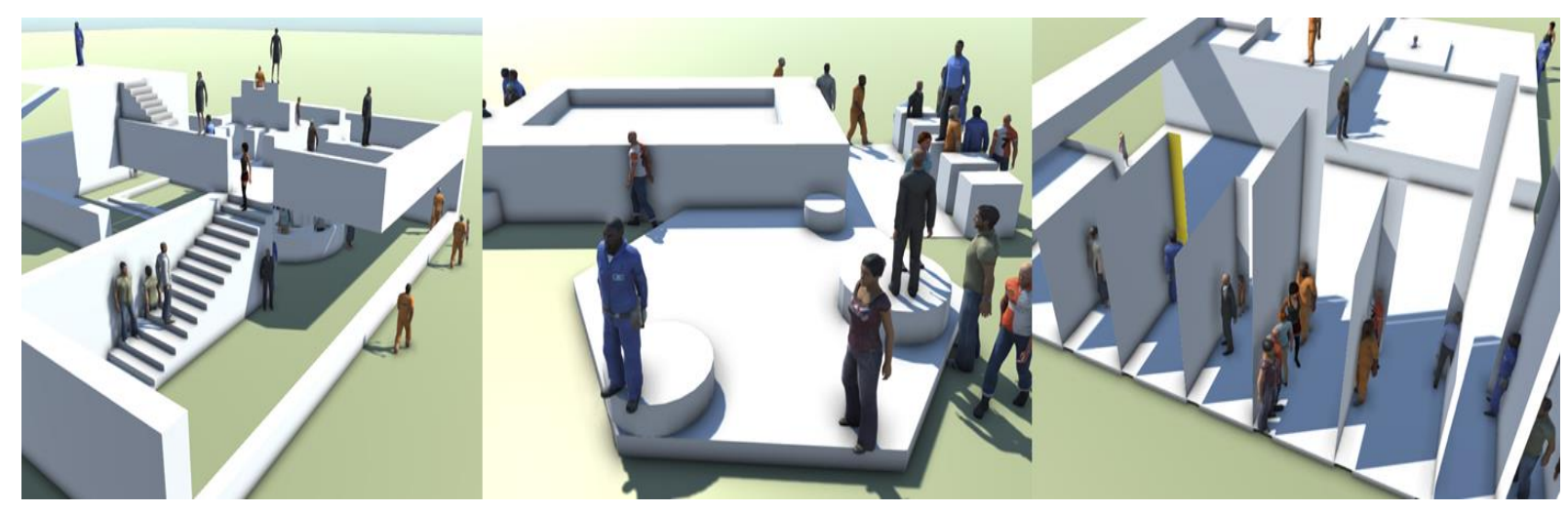

[Fig. 2] Human Behavior Simulation using Intelligent Agents (Hong \& Lee, 2019)[3]

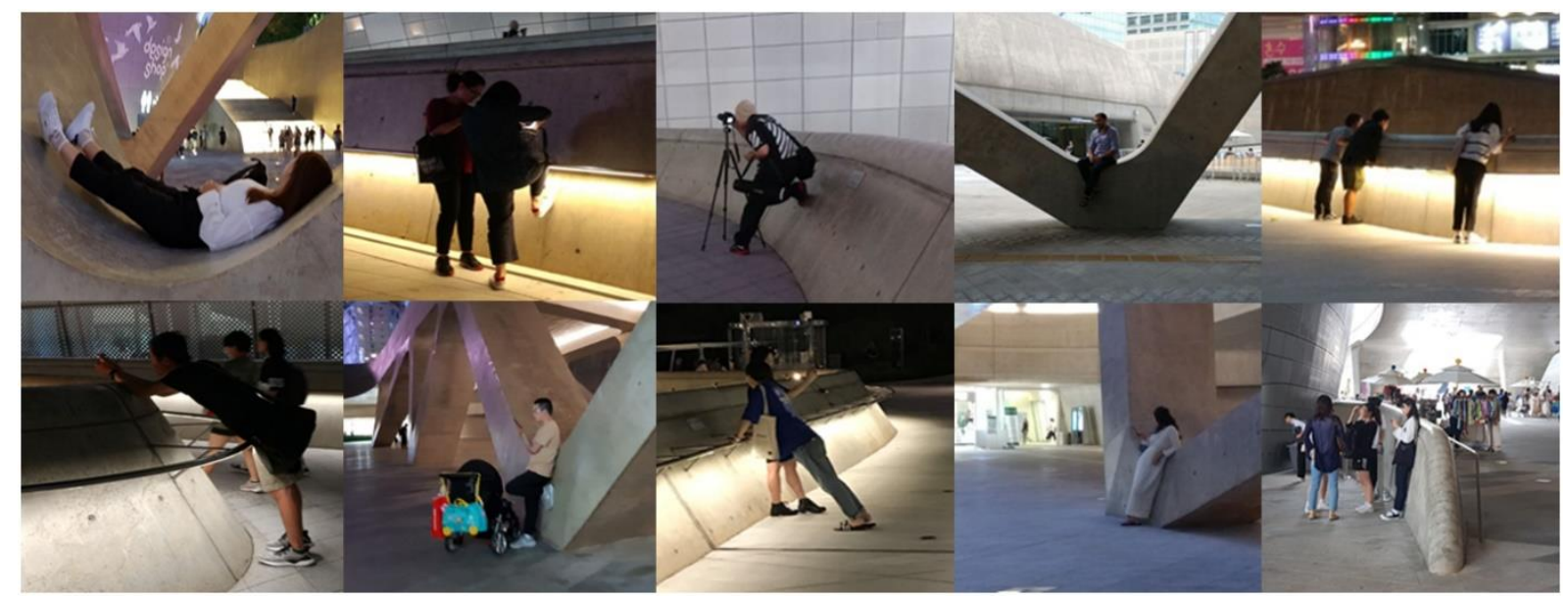

[Fig. 3] Human Behaviors in the Atypical Shaped Building

Recently, the social demand for atypical architecture is increasing. Architects need to develop their ability to design atypical buildings, and the Department of Architecture needs to teach students how to design atypical buildings. As mentioned earlier, when designing atypical buildings, architects focus on unusual shapes, so consideration of human factors sometimes can be insufficient. In addition, since the shape of an atypical building is what the architect has not experienced before, it is difficult to predict user behavior in a designed atypical building. [Fig. 3] shows the user's behavior in an atypical building. For this reason, human behavior simulation using virtual users is required in the design process of an atypical building. In other words, by deploying intelligent virtual users in a designed atypical building and observing their behavior, the architect can comprehend the performance of the human factor of the designed atypical building[5][6].

[Fig. 4] shows Representation of human figures in atypical architectural design. Lee (2018) says that through his research, the reproduction of human behavioral images in the process of designing atypical buildings helped to find creative problems[7]. This is a proof of the usefulness of intelligent 
human behavior simulation in the design process of atypical buildings. Hong \& Lee (2019) says in his research that expressions of various human behaviors reinforce the effect of simulation[3]. In other words, it can be said that human behavior simulation using intelligent virtual users performing various actions provides an environment for examining human factors to architects in the process of atypical architectural design.
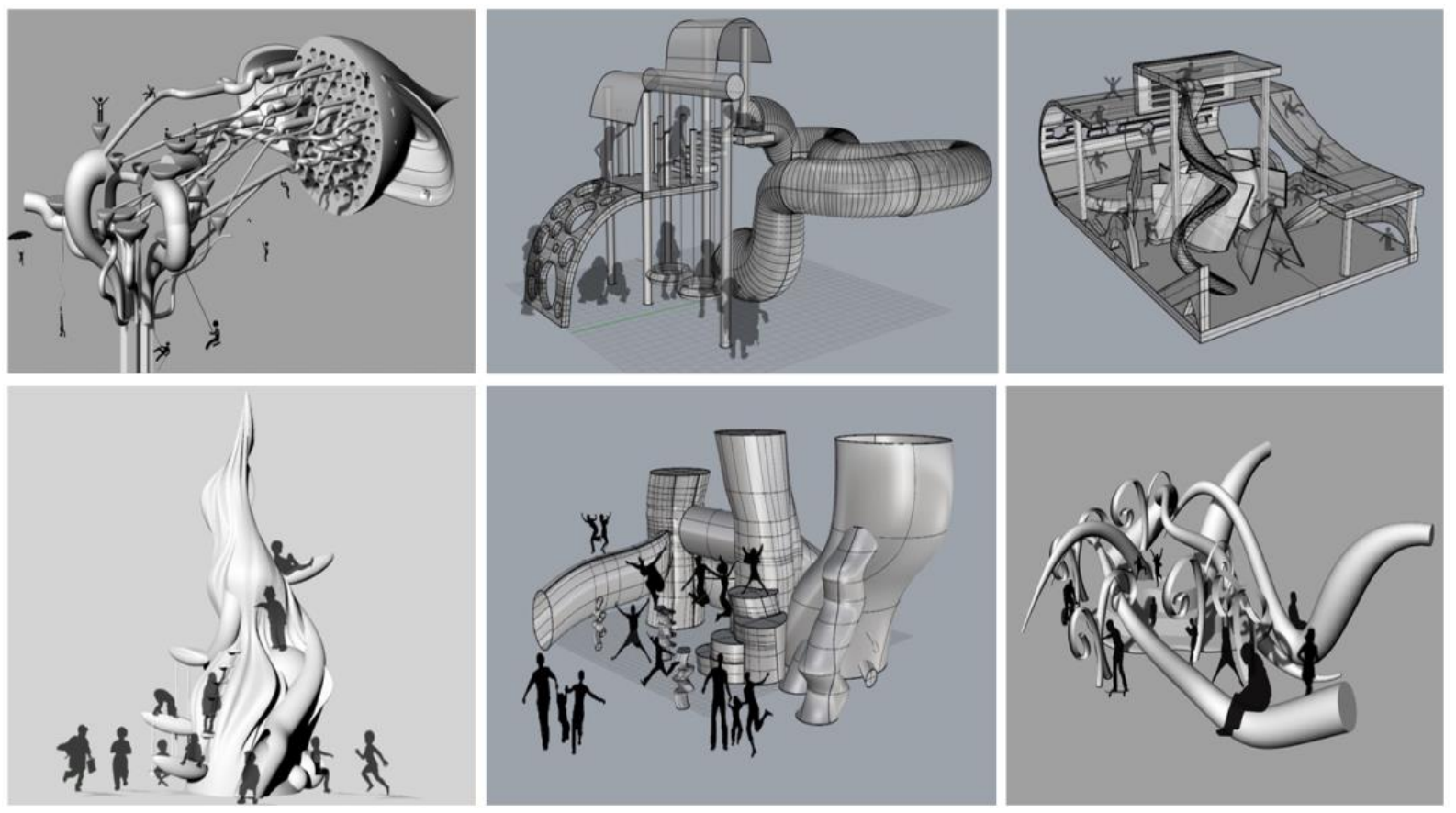

[Fig. 3] Representation of Human Figures in Atypical Architectural Design (Lee, 2018)[7]

\section{Autonomous Adaptive Behavior In Actoviz}

[Fig. 5] illustrates the process of using ActoViz with Rhino and Grasshopper in the process of atypical design. It is not easy for the virtual agent to react appropriately to the atypical shapes designed by students, because they are quite complicated and unusual. Virtual users behave according to prerecorded behaviors when they arrive at the designed place. In the virtual environment based on atypical geometries, virtual agent behaves inappropriately because pre-recorded behavior data could be not exactly match to devious shapes. This limitation of virtual user could decline the effect of human behavior simulation. In the previous research, we solve this limitation to develop the functions of adaptive behavior in ActoViz.

To create a natural human behavior simulation in ActoViz, we developed an autonomous behavior function using ragdoll physics and model predictive control (MPC). Ragdoll physics is a kind of physics engine routine animation that is often used as a extra for conventional still death cartoons in video games and animated films. The concept of MPC has traditionally been used in biochemical plants, factories, and power organizations, but it is also used as a way of character animation[8][9].

When ragdoll physics are applied in ActoViz, the virtual user (VUser) reacts in various ways to unequal shapes and unusual geometry, permitting a more expected user conduct simulation. [Fig. 6] compares human behaviors with and without ragdoll physics in ActoViz. As shown in [Fig. 6], ragdoll physics can prevent the VUser from getting stuck in atypical geometry. In ActoViz, MPC enables the VUser to appropriately interact with numerous atypical geometric shapes. For example, as shown in [Fig. 7], when the VUser ascents a vertical slope, it responds by balancing; when it falls, it reacts appropriately to the atypical geometry. 


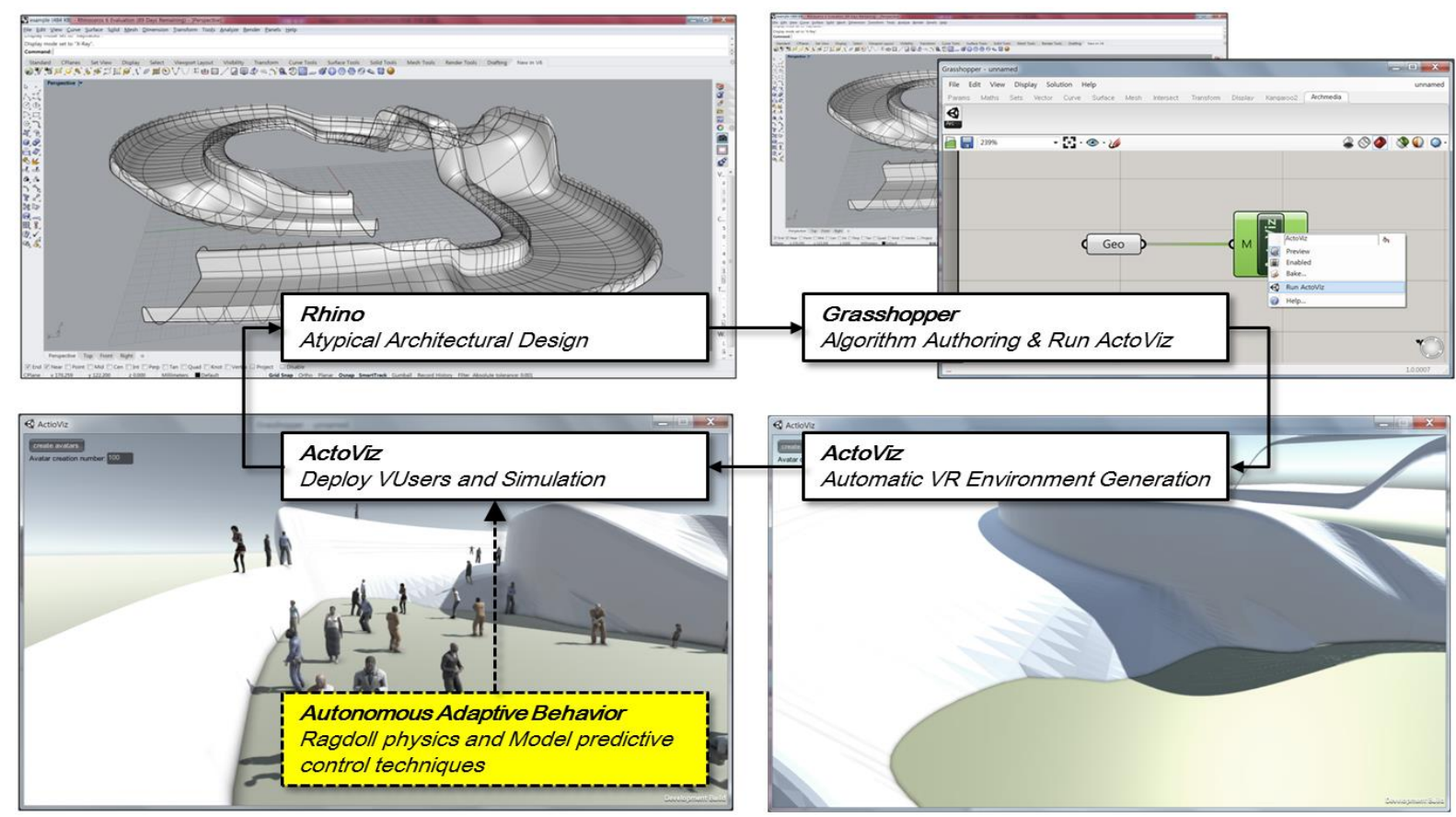

[Fig. 5] A Human Behavior Simulation using Autonomous Adaptive Behavior [4]
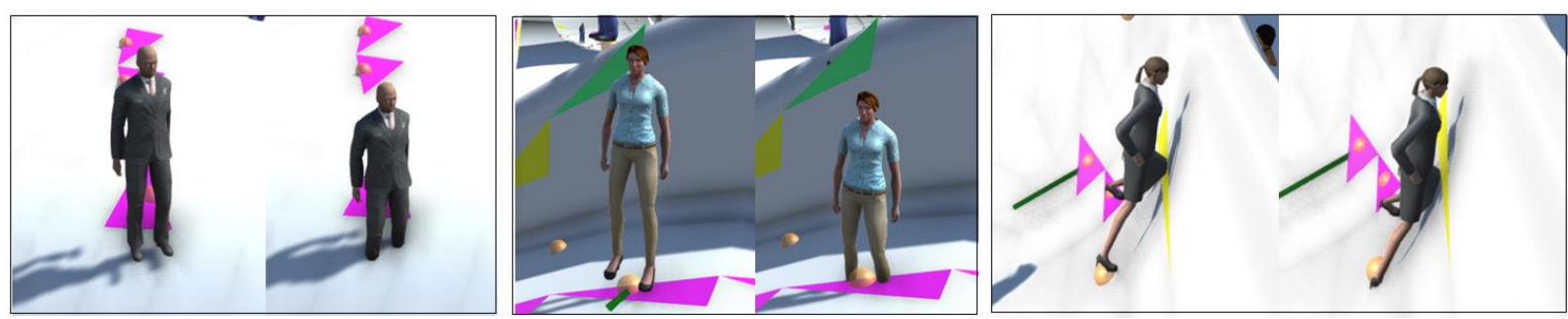

[Fig. 6] ActoViz with (Left) and without (Right) Ragdoll Physics [4]

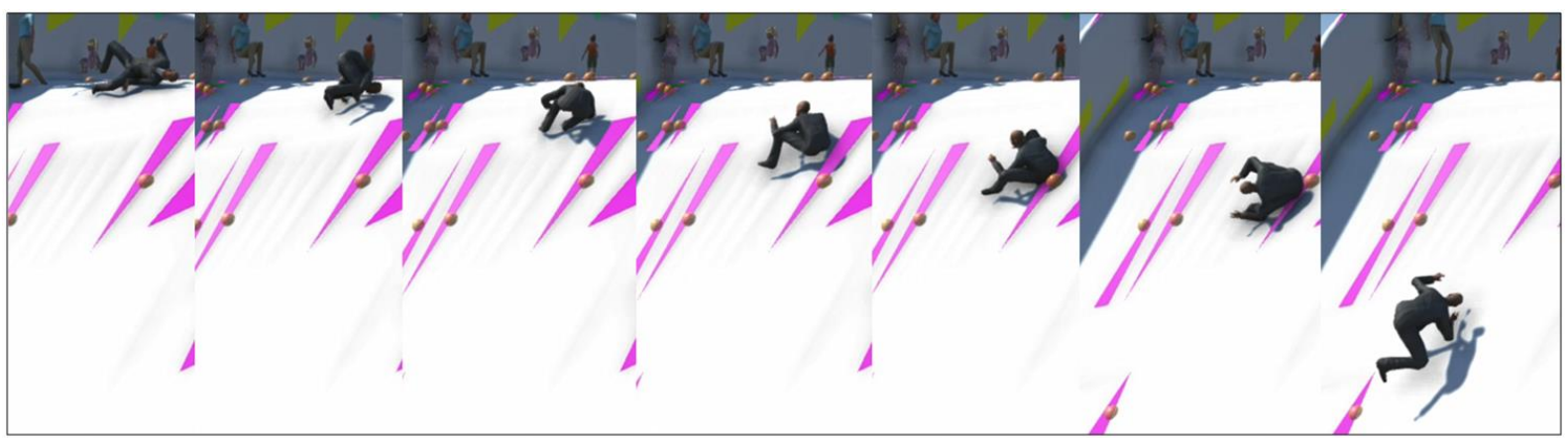

[Fig. 7] Motion Predictive Control in ActoViz (During a Fall)[4]

\section{The Effect of Autonomous Adaptive Behavior On Creative Problem Finding in Atypical Architectural Design}

\subsection{Background}

In modern psychology, creativity refers to an idea that combines novelty and functionality. Therefore, creative thinking requires a personal experience in which a designer acquires new and useful ideas to solve a given problem or achieve a purpose. From a pedagogical point of view, the 
emphasis is on developing students' heuristic creativity. Models that reproduce human behavior can help students develop ideas related to functionality, one element of creativity. When a design is revised based on user behaviors, the designer can think deeply about the size and shape of the space and its relationship with users. In addition, the designer can predict how users and residents will behave in the space, and architectural elements can be designed based on models of human behavior. Such models also enable a designer to evaluate the usefulness of the space. In addition, reproducing human behavior can help designers develop novel ideas about the forms of architectural spaces and elements. Various human morphological representations can function as visual stimulators that can explore the shape and proportion of buildings from various perspectives. This invites a new way of thinking and possibility that highlights a design's functionality for humans by using a human simulation to interact with an architectural space. Furthermore, extracting a human form, which is a characteristic of representation, enables a new way of interpreting the building space. Based on this theoretical background and related research, the present study examines creative problem finding and investigates the effects of virtual users' adaptive behavior on creative problem finding using design experiments and questionnaires[10][11].
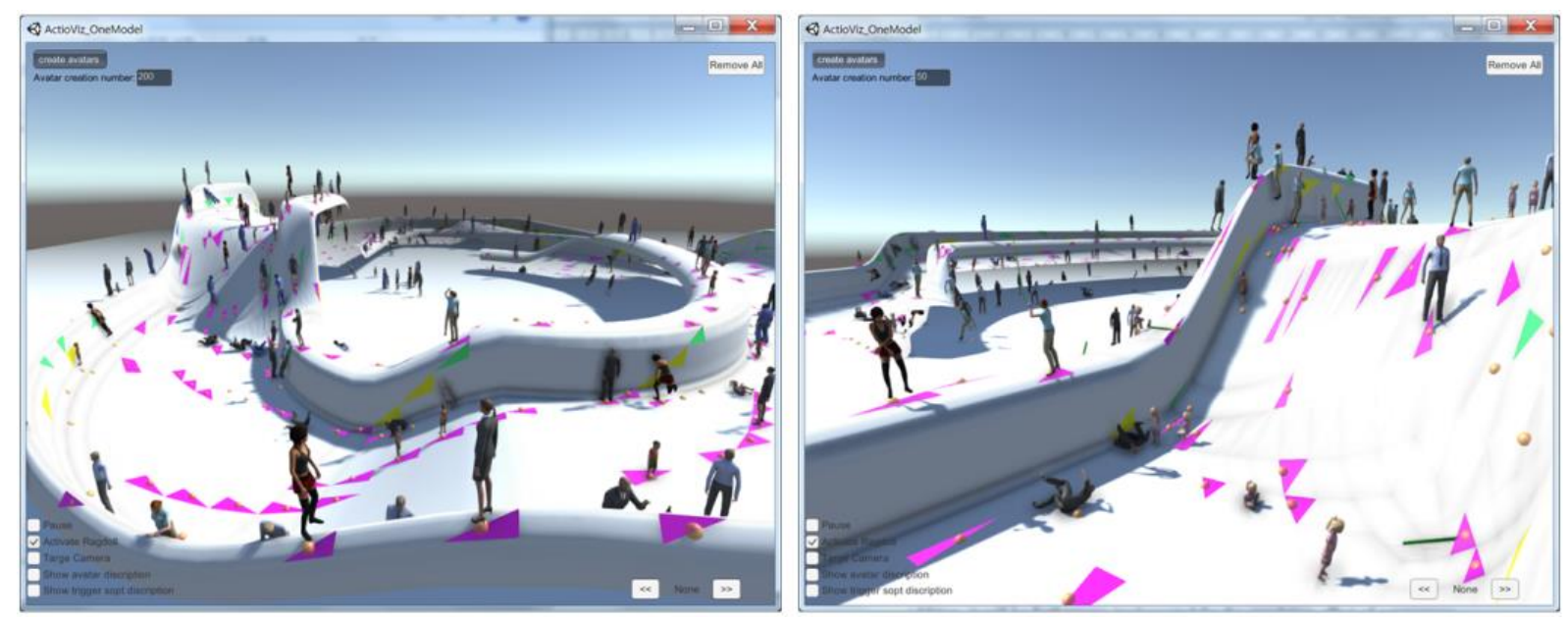

[Fig. 8] Autonomous Adaptive Behaviors for Human Behavior Simulation of an Atypical Architectural Space in ActoViz

\subsection{Method}

During the 2020 Spring Semester, 35 students enrolled in a seminar on computer-aided architectural architecture called Digital Design Lab 1. They were all third-year students at H University in South Korea with a degree in architecture, which is a five-year technical program. One of the goals of this course is to teach students to create new architectural types using a digital modeling platform. The teacher asked the students to build a playground that would encourage children to take part in various games using different styles of spaces and sculptures. The students used Rhino 3D, a digital modeling tool that allowed them to freely model atypical shapes, to design the playgrounds.

In the classroom, each student built a playground and designed a digital interface model. They designed physical shapes for human use on the basis of their own previous experience and knowledge. Next, the students conducted the ActoViz human behaviour simulation on their projects. During this human behavior simulation, the adaptive behavior function of ActoViz was switched on and off several times. They have used modeling to define and fix issues in their projects. This modeling process was replicated several times by the students using Rhino and ActoViz. [Fig. 8] shows autonomous adaptive behaviors for human behavior simulation of an atypical architectural space in actoviz. [Fig. 9] shows students' work for atypical playgrounds designed using Rhino (left) and user 
simulations in ActoViz (right)[12][13].

After finishing these playground design tasks, the students compared their design results before and after they used the adaptive behavior function to evaluate human interactions with their design. They then responded to a questionnaire about the usefulness of the adaptive behavior function to the design process. The questionnaire used a seven-point Likert scale ( $0=$ not at all; $7=$ very much). The criteria focused on creative problem finding and included the following statements (the students indicated their agreement or disagreement): (1) The adaptive behavior function helped improve the quality of your atypical spatial design; (2) The function facilitated the process of planning an atypical space; (3) The function increased your confidence in the usefulness/rationality of the final design; (4) The function helped you design new shapes; (5) The function helped you design various functions for the space; (6) The function improved the design's safety and convenience; (7) The function helped you plan an appropriate atypical space; and (8) The function helped you identify problems and design errors. These criteria were based on prevailing creativity principles that were changed to match the context of the given design tasks[14].
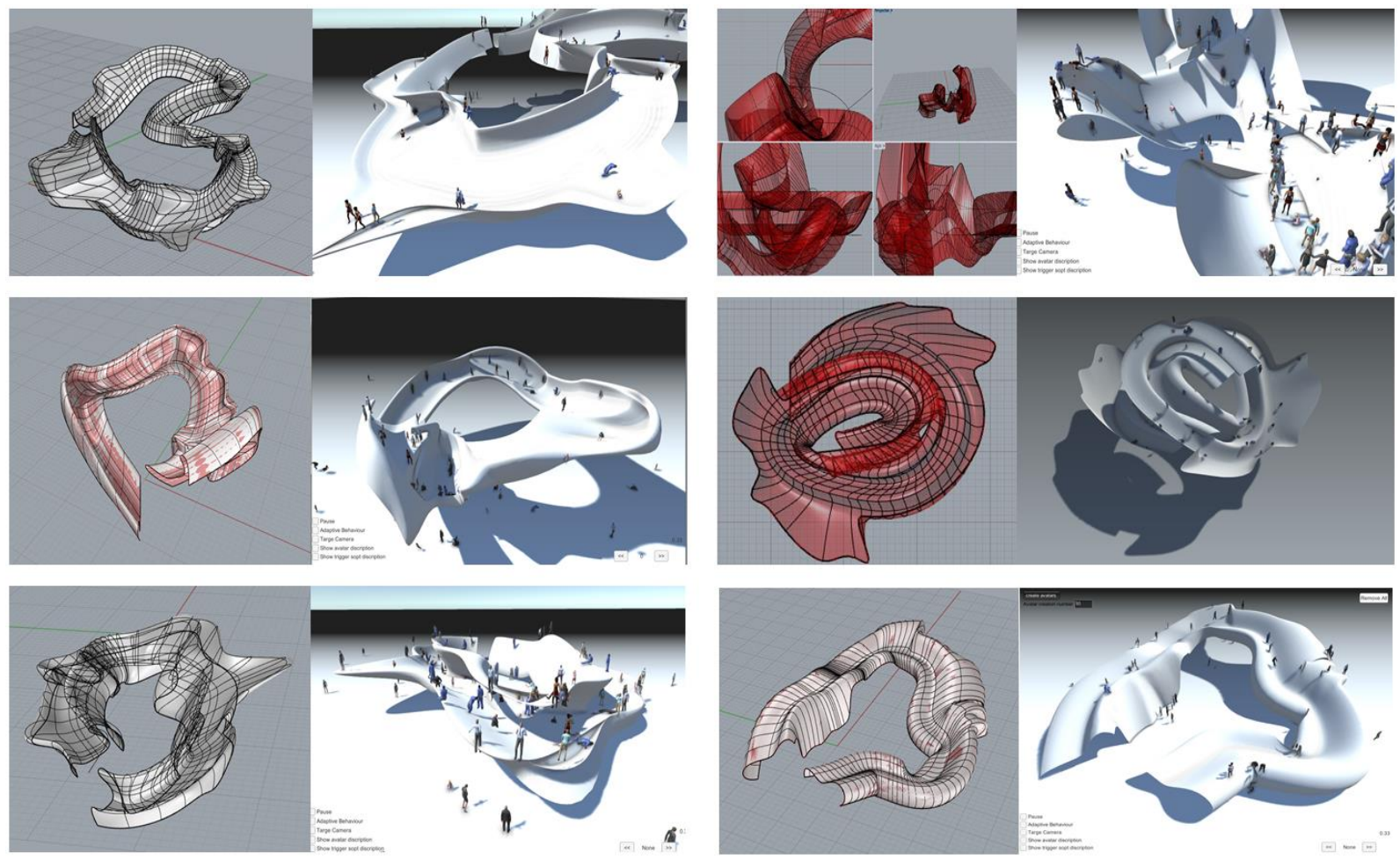

[Fig. 9] Six students' work: atypical playgrounds designed using Rhino (left) and user simulations in ActoViz (right)

[Table 1] Paired-samples t-tests on Creative Problem Finding before and after using the Autonomous Adaptive Behavior Function

\begin{tabular}{|l|c|c|c|c|}
\hline \multirow{2}{*}{} & \multicolumn{2}{|c|}{ M (SD) } & \multirow{2}{*}{$\begin{array}{c}\text { Mean } \\
\text { Difference }\end{array}$} & P \\
\cline { 2 - 3 } & $\begin{array}{c}\text { Before Autonomous } \\
\text { Adaptive Behaviors } \\
(\mathrm{n}=35)\end{array}$ & $\begin{array}{c}\text { After Autonomous } \\
\text { Adaptive Behaviors } \\
(\mathrm{n}=35)\end{array}$ & 0.197 & 0.845 \\
\hline $\begin{array}{c}\text { (1) Helped improve the } \\
\text { quality of your atypical } \\
\text { spatial design }\end{array}$ & -0.26582 & 0.32296 & -0.709 & 0.483 \\
\hline (2) Facilitated the process of & -0.55222 & 0.26651 & \\
\hline
\end{tabular}




\begin{tabular}{|c|c|c|c|c|}
\hline \multicolumn{1}{|c|}{ planning an atypical } & & & \\
space & -0.92159 & -0.04984 & -2.265 & $0.030^{*}$ \\
\hline $\begin{array}{c}\text { (3) Increased your } \\
\text { confidence in the } \\
\text { usefulness/rationality of } \\
\text { the final design }\end{array}$ & -0.99999 & -0.29412 & -3.730 & $0.001^{*}$ \\
\hline $\begin{array}{c}\text { (4) Helped you design new } \\
\text { shapes }\end{array}$ & -0.89032 & -0.13825 & -2.779 & $0.009^{*}$ \\
\hline $\begin{array}{c}\text { (5) Helped you design } \\
\text { various functions }\end{array}$ & -1.15390 & -0.04610 & -2.201 & $0.035^{*}$ \\
\hline $\begin{array}{c}\text { (6) Improved safety and } \\
\text { convenience }\end{array}$ & -0.63144 & 0.28858 & -0.757 & 0.454 \\
\hline $\begin{array}{c}\text { (7) Helped you plan an } \\
\text { appropriate atypical } \\
\text { space }\end{array}$ & -0.94346 & -0.11536 & -2.601 & $0.014^{*}$ \\
\hline $\begin{array}{c}\text { (8) Helped you identify } \\
\text { problems and design } \\
\text { errors }\end{array}$ & & & & \\
\hline
\end{tabular}

\subsection{Results}

A paired-sample t-test was accompanied to compare student self-assessment scores on the creative problem finding before and after using the adaptive behavior function to evaluate their designs.

Regarding statement (3), the t-test indicated that the students had more confidence in the usability and value of their designs after using the adaptive behavior function $(\mathrm{M}=4.20, \mathrm{SD}=0.96)$ than before they used the function $(\mathrm{M}=3.71, \mathrm{SD}=1.01 ; \mathrm{t}(35)=-2.265, \mathrm{p}<.030)$. In response to statement (4), the students indicated that they were better able to design new shapes after using the adaptive behavior function $(\mathrm{M}=4.52, \mathrm{SD}=0.96)$ than before $(\mathrm{M}=3.88, \mathrm{SD}=0.84 ; \mathrm{t}(35)=-3.730, \mathrm{p}<.001)$. The responses to statement (5) indicated that the adaptive behavior function helped the students find more varied functions for their designs. The responses to statement (6) showed that the students felt more confident in their designs' safety and convenience after using the adaptive behavior function $(\mathrm{M}=$ $4.40, \mathrm{SD}=1.03)$ than before $(\mathrm{M}=3.80, \mathrm{SD}=1.25 ; \mathrm{t}(77)=-2.201, \mathrm{p}<.035)$. The responses to statement (8) indicated that the adaptive behavior function helped the students identify more design problems and errors .

However, as Table 1 shows, no statistically significant results were observed in the responses to statements (1), (2), and (7). Based on the analysis data, it was found that the adaptive behavior function did not help the students go through the overall design process or produce appropriate design results.

\section{Discussion And Conclusion}

This study examined the effect of an adaptive behavior function on a human behavior simulation. Student designers used a human behavior simulation with an adaptive behavior function during the design of atypical architectural spaces, then, the designers responded to a questionnaire about the adaptive behavior function and creative problem finding. The results of the questionnaire were then analyzed using a paired t-test technique, resulting in several statistically significant findings. According to the analysis, the adaptive behavior function helped increase the usefulness and rationality of the designs. 
The adaptive behavior function enables a more precise and humanlike behavioral response to shapes in an atypical architectural space. The survey showed that the adaptive behavior function helped designers create new shapes and identify more functions for their designs. This suggests that the adaptive behavior function helped designers develop new forms of architectural space. The survey results also indicated that the adaptive behavior function helped designers identify problems in their designs, increasing their confidence in the designs' safety and convenience. This is because the adaptive behavior function expresses the physical situation better than other behavior simulations, so designers can see when the VUser falls down[15][16].

The statistically insignificant results in the analysis were mainly related to supporting the design process or to the overall design results. The results of the statistical analysis for these questions may have been insignificant because the adaptive behavior function is not complete and was inconvenient to use. In addition, the behavior of the VUser influences the design shapes more than it does the overall design process.

Based on the findings of this study, the researchers conclude that the adaptive behavior function is beneficial for the design of atypical spaces. However, since the sample included only 35 students and the analysis resulted in high standard deviations, additional research incorporating more participants is needed. It is also necessary to adjust the adaptive behavior function so that it operates more smoothly on ActoViz.

In the future research, not only technical but also theoretical research should be added. In terms of technology, it is necessary to develop ActoViz's VUsers so that they can perform more natural behaviors on unstructured architectural forms. In addition, since the user's response behavior to the physical space and the interaction between users are involved in an actual atypical building, it is necessary to upgrade VUsers to enable social interaction. In the theoretical aspect, it is necessary to consider how the psychological situation of the user, changes in surrounding circumstances, and relationships with other users can affect the expression of creativity.

\section{Acknowledgments}

This work was supported by the National Research Foundation of Korea (NRF) grant funded by the Korea government (MSIT) (NRF-2018R1A2B6005827).

\section{References}

[1] Y. J. Han, H. J. Lian, Dynamic Assessment of Human Resource Management on Organizational Effectiveness based on Network Platform, International Journal of Smart Home, (2016), Vol.10, No.4, pp.279-288.

[2] C. U. Lee, J. H. Lee, R. D. Oh, System Management of Human Object on the Industrial Safety, International Journal of Smart Home, (2016), Vol.10, No.5, pp.171-182.

[3] S. W. Hong, Y. G. Lee, Behavioural responsiveness of virtual users for students creative problem finding in architectural design, Architectural Science Review, (2019), Vol.62, No.3, pp.238-247.

[4] Y. G. Lee, Developing autonomous adaptive behavior for human behavior simulation of an atypical architectural Space, Communications in Computer and Information Science, (2020), Vol.1225, pp.188-192.

[5] X. Niu, Z. Wang, W. Xiao, Z. Pan, Uncertainty Sampling Based Posterior Probability Extreme Learning Machine for Human Activity Recognition, International Journal of Smart Home, (2016), Vol.10, No.11, pp.95-108.

[6] X. Zhou, W. Shen, Research on Interactive Device Ergonomics Designed for Elderly Users in the Human-Computer Interaction, International Journal of Smart Home, (2016), Vol.10, No.2, pp.49-62. 
[7] Y. Lee, A study on the effect of human factor for atypical design in the architectural design studio, Advances in Intelligent Systems and Computing, (2018), Vol.876, No.1, pp.130-134.

[8] M. Watkinson, Real Time Character Animation: A Generic Approach to Ragdoll Physics, Coventry University, Master's Thesis, (2009)

[9] C. E. Garcia, D. M. Prett, M. Morari, Model predictive control: theory and practice a survey, Automatica, (1989), Vol.25, No.3, pp.335-348.

[10] S. W. Hong, Y. G. Lee, A Study on the Effectiveness of Using Human Behavior Representation on Creative Motivation in Architectural Design Process, Journal of the Architectural Institute of Korea Planning \& Design, (2014), Vol.30, No.3, pp.93-100.

[11] M. A. Runco, Creativity: Theories and themes: Research, development, and practice, Academic Press, (2014).

[12] S. W. Hong, D. Schaumann, Y. E. Kalay, Human behavior simulation in architectural design projects: An observational study in an academic course, Computer, Environment, and Urban Systems, (2016), Vol.60, pp.1-11.

[13] D. Simeone, Y. E. Kalay, D. Schaumann, S. Hong, Modeling and simulating use processes in buildings, 2013 Proceedings of Education and Research in Computed Aided Architectural Design in Europe, (2013), pp.59-66.

[14] M. A. Boden, Creativity and Arts: Three Roads to Surprise, Oxford University Press, (2012)

[15] Y. Chang, Y. Chien, H. Lin, M. Chen, H. Hsieh, Effects of 3D CAD applications on the design creativity of students with different representational abilities, Computer in Humans Behavior, (2016), Vol.65, pp.107-113.

[16] G. Goldschmidt, Linkography, MIT Press, (2014) 